\title{
HETEROCHRONY IN MOSASAUR EVOLUTION AS SUGGESTED BY GEOMETRIC MODELS OF HUMERI
}

MASSARE*, Judy A., The Earth Sciences Dept., SUNY College at Brockport, NY 14420 and Rochester Institute of Vertebrate Paleontology, 928 Whalen Road, Penfield, NY 14526 ; SHELDON, M. Amy, Geology and Geography Dept., University of South Alabama, Mobile, AL 36660 and Rochester Institute of Vertebrate Paleontology, 928 Whalen Road, Penfield, NY 14526.

Mosasaurs are marine lizards that diversified rapidly during the Late Cretaceous. The major North American genera have distinct humerus morphologies, and in some genera, the humerus morphology can distinguish species within the genus. A three-dimensional model of a Clidastes humerus was produced using a constructional geometry program. The central shaft of the humerus was modeled as two cones that meet at their apices and are oriented with their axes along the length of the humerus (after Felts and Spurell, 1966). These cones reflect the process by which the bone actually grows and are observable in many aquatic vertebrates which lack a medullary cavity in their limb bones (Felts and Spurell, 1966; Rhodin, 1985). The processes for muscle attachment are five smaller, accessory cones that radiate from the middle of the bone shaft. A tremendous amount of diversity can be produced by changing the dimensions (= expansion rates) and relative sizes (= relative growth rates) of the main and accessory cones.

By changing four parameters: (1) the expansion rate of the main cones, (2) the orientation of the accessory cones, (3) the expansion rate of accessory cones, and (4) the growth rate of accessory cones relative to the main cones, the humerus morphologies of the common North American mosasaurs can be generated from the Clidastes model. The expansion rate of the main cones determines the overall humerus dimensions. The orientation of accessory cones is closely tied to the shape of the main cones. A change in the expansion rate of an accessory cone makes the process more or less prominent relative to the main cones. The position of the process along the shaft can be changed by altering the size of accessory cone, equivalent to changing its growth rate. The influence of rate changes on morphology suggests that heterochrony may have been a major mechanism for mosasaur diversification.

Mosasaur humeri are wider, shorter, and generally dorso-ventrally compressed compared to humeri of typical terrestrial lizards. Using the Clidastes model, a "terrestrial" limb can also be generated by larger changes in the same parameters described above. Heterochrony thus may have been important in the initial divergence of mosasaurs from terrestrial lizards. These results may have a wider application. Vertebrates in general display a wide range of limb morphologies and many limb specializations. Differences in rates and relative rates may be responsible for the wide range of morphologies which are observed.

Felts, W. J. L. and F. A. Spurrell. 1966. Some structural and developmental characteristics of Cetacean (Odontocete) radii. A study of adaptive osteogenesis. American Journal of Anatomy, 118: 103-134.

Rhodin, A. G. J. 1985. Comparative chondro-osseous development and growth of marine turtles. Copeia 1985: 752-771. 